\title{
DESAFIOS PARA O CONTROLE DE INFECÇÃO NAS INSTITUIÇÕES DE SAÚDE: PERCEPÇÃO DOS ENFERMEIROS
}

\author{
CHALLENGES IN INFECTION CONTROL IN HEALTH INSTITUTIONS: \\ NURSE'S PERCEPTIONS
}

\author{
DESAFIOS PARA EL CONTROL DE INFECCION EN LAS INSTITUCIONES \\ DE SALUD: PERCEPCION DE LOS ENFERMEROS
}

\section{ADENÍCIA CUSTÓDIA SILVA E SOUZA ${ }^{1}$, ANACLARA FERREIRA VEIGA TIPPLE ${ }^{1}$, MILCA SEVERINO PEREIRA ${ }^{1}$, MARINÉSIA APARECIDA DO PRADO ${ }^{2}$}

\begin{abstract}
RESUMO
A multiplicidade de fatores que envolve o controle das infecções tem dificultado a implementação de um efetivo programa de prevenção e controle e representa desafios cada vez maiores aos profissionais de saúde. Este estudo de abordagem qualitativa visa identificar, entre os enfermeiros, os desafios para o controle de infecção hospitalar. Participaram do estudo enfermeiras candidatas ao curso de especialização em controle de infecção hospitalar. Os relatos foram obtidos por livre registro das participantes que, a partir de suas experiências e visões discorreram acerca da questão norteadora: os desafios no controle de infecção nas instituições de saúde. Após leitura exaustiva, apreendemos seis categorias de análise que englobam em suas estruturas, subcategorias explicitadas pelos sujeitos como desafios para o controle de infecção: estrutura organizacional; batalha biológica; envolvimento profissional; capacitação profissional; epidemiologia das infecções; medidas de prevenção e controle. Os desafios encontrados vão desde a adoção de medidas simples de controle até a complicada estrutura organizacional das instituições normatizadoras, provedoras e executoras. Entretanto, os maiores desafios apontados foram as políticas instituídas, as relações de trabalho e o pouco envolvimento dos profissionais.
\end{abstract}

Palavras chaves: Controle de infecção, Desafios, Percepção de enfermeiros.

\begin{abstract}
The multiplicity of factors that involves the control of infections has been hindering the implementation of an effective prevention program and control and day-to-day represents a larger challenge to the professionals of health. This study of qualitative approach seeks to identify, among the female nurses, the challenges for the nosocomial infection control. The subjects in the study, are nurses candidates to the specialization course in nosocomial infection control. The reports were obtained through the participants' free registration which from their experiences and visions related the challenges in the infection control in the institutions of health where they work. After exhaustive reading we apprehended six analysis categories: organizational structure; biological battle; professional involvement; professional training; epidemiology of the infections; prevention measures and control. The challenges quoted include since the adoption of simple measures of control until the complicated organizational structures of the institutions that make norms, suppliers and executors. However, the largest challenges shown were the politics of each institution, the work relationships and the professionals' little involvement.
\end{abstract}

Keywords: Infection control, Challenges, Nurse's perception.

${ }^{1}$ Enfermeiras, professoras, doutoras da Faculdade de Enfermagem da Universidade Federal de Goiás, Brasil.

${ }^{2}$ Enfermeira, professora da Faculdade de Enfermagem da Universidade Federal de Goiás e mestranda da Escola de Enfermagem da Universidade de São Paulo, Brasil. 


\section{RESUMEN}

La multiplicidad de factores que involucran el control de las infecciones ha estado impidiendo la implementación de un eficaz programa de prevención y control y representa desafíos cada vez más grandes a los profesionales de salud. Este estudio de abordaje cualitativo busca identificar, entre las enfermeras, los desafíos para el control de infección hospitalaria. Participaron en el estudio candidatas al curso de la especialización en control de infección hospitalaria. Los informes fueron obtenidos por el registro libre de los participantes que, a partir de sus experiencias y visiones, describieron los desafíos en el control de infección en las instituciones de salud. Después de la lectura exhaustiva, nosotros aprehendimos seis categorías del análisis: estructura organizacional; batalla biológica; envolvimiento profesional; capacitación profesional; epidemiología de las infecciones; medidas de prevención y control. Los desafíos encontrados van de la adopción de medidas simples de control a la complicada estructura organizacional de las instituciones normadoras, proveedoras y ejecutoras. Sin embargo, el más grande desafío explicitado fue la política instituida, las relaciones de trabajo y el escaso compromiso de los profesionales.

Palabras claves: Control de infección, Desafíos, Percepción de enfermeros.

\section{INTRODUÇÃO}

As infecções hospitalares existem desde a Idade Média, mas só na década de 50 foram reconhecidas como um problema de saúde pública e a partir de então discutidas nos eventos científicos e organismos internacionais como a Organização Mundial de Saúde (OMS) e a Organização Panamericana de Saúde (OPS).

No Brasil, na década de 70, alguns hospitais públicos começaram, de forma isolada, a se preocupar com as infecções hospitalares (IH), estabelecendo algumas medidas de prevenção e controle (11).

A partir da década de 80, o assunto tornase objeto de ações governamentais com a publicação das portarias de $\mathrm{N}^{\mathrm{o}}$ 196/83, 930/92, 2.616/98 do Ministério da Saúde (MS) que normatizam e regulamentam medidas de prevenção e controle de infecção hospitalar $(2,3,4)$. Vários Centros de Treinamentos foram criados em todo o país e cursos de capacitação para o controle das IH foram realizados. O tema é, então, amplamente socializado entre as instituições e profissionais de saúde.

Começa-se a luta pelo controle das infecções adquiridas nas unidades de internação. Muitas barreiras foram encontradas, desde a caracterização do que é uma infecção hospitalar e como diagnosticá-la, até formas de prevenção e controle.

Apesar da determinação do MS de que todos os hospitais devem criar e manter Comissões de Controle de Infecção Hospitalar $(\mathrm{CCIH})$ em funcionamento, na prática isso não ocorreu e, segundo Lacerda et al. e Pereira $(8,11)$, devido às diferentes condições apresentadas pelos hospitais, às resistências encontradas e aos processos de poder que se intercalaram no curso de suas operacionalizações.

As CCIH que se estruturaram e estão em funcionamento, enfrentam as dificuldades naturais de um serviço novo. Seu enfoque maior está centrado nos levantamentos epidemiológicos, até pela necessidade de conhecerem a realidade a partir da qual se estabeleceriam as ações de controle.

Apesar dos esforços e da contribuição da pesquisa que tem retroalimentado as ações de controle, a IH segundo Pereira et al. (12) continua representando uma séria ameaça à segurança dos pacientes hospitalizados e tem contribuído para elevar as taxas de morbi-mortalidade e aumentar os custos hospitalares.

O controle das IH engloba vários aspectos, como: políticas de saúde e administrativas, recursos econômicos, planta física, capacidade e engajamento profissional, conhecimento das características dos microrganismos e das interrelações existentes entre eles. Esta multiplicidade de fatores tem dificultado a implementação de um efetivo programa de prevenção e controle das IH e representa desafios cada vez maiores aos profissionais de saúde que se propõem a eliminá-las. 
Assim sendo, pretendemos conhecer os reais desafios para o controle de infecção, conforme explicitados por enfermeiras.

\section{PERCURSO METODOLÓGICO}

O delineamento do estudo teve uma abordagem qualitativa, fundamentado em uma questão norteadora "Discorra sobre o desafio do controle de infecção nas instituições de saúde" que foi aplicada a enfermeiras, candidatas ao processo seletivo para o curso de especialização em controle de infecção hospitalar da Faculdade de Enfermagem da Universidade Federal de Goiás.

Esta questão foi avaliada do ponto de vista do conhecimento e visão do controle de infecção. A população estudada foi 36 enfermeiras que atuam no controle de infecção. Os relatos foram obtidos através do livre registro das candidatas, que concordaram em participar do estudo através da assinatura no termo de livre consentimento, e que à partir de suas experiências e visões discorreram acerca dos desafios no controle de infecção nas instituições de saúde.

Para a análise dos resultados utilizamos a técnica de análise temática (1). Procedemos a uma leitura dos dados, extraímos os fragmentos que abordavam a questão norteadora e os agrupamos em temas e idéias semelhantes explicitadas pelos sujeitos. Numa segunda leitura, mais detalhada, nomeamos seis categorias de análise: estrutura organizacional; batalha biológica; envolvimento profissional; epidemiologia das infecções; capacitação profissional e; medidas de prevenção e controle.

A partir destas categorias surgiram outras subcategorias relevantes que constituíam detalhamento do foco central.

Estabelecidas as categorias e subcategorias procedemos a análise qualitativa, confrontando os relatos com o referencial teórico do controle de infecção. Os fragmentos de registros utilizados neste estudo receberam um código composto pela letra " $E$ " de enfermeiro e um número com dois algarismos correspondente a ordem de entrega das respostas.

\section{ESTRUTURA ORGANIZACIONAL}

A efetivação das ações da CCIH na visão dos sujeitos deste estudo depende da estrutura e apoio organizacional da instituição através de suas políticas institucionais e administrativas, das relações de trabalho em nível interpessoal e intersetorial, da normatização do serviço e, num âmbito maior, das políticas governamentais. E estes representam grandes desafios a serem vencidos para o controle das infecções.

\section{Políticas Governamentais}

Estas enfermeiras que atuam no controle das infecções demonstraram claramente os desafios encontrados para a efetivação deste controle através dos registros que fizeram, onde destacaram a falta de apoio e a escassez de verbas destinadas a sustentar os programas de prevenção das infecções hospitalares.

“... dependemos da atuação, compreensão e decisão de autoridades governamentais, que nem sempre ocorre". E26.

"Descaso por parte dos governantes que não priorizam uma política de saúde e educação, não investe o mínimo necessário". E34.

"Sistema de saúde em nível Nacional - má distribuição de renda para a saúde". E07.

"... recursos econômicos direcionados à saúde em quantidade insuficiente". E19.

Estes relatos evidenciam a percepção de enfermeiros quanto à política de distribuição de verbas para a saúde e em especial para o investimento em prevenção e controle das infecções hospitalares.

Outro desafio a ser vencido e citado com muita freqüência pelos sujeitos foi a existência de CCIH fantasmas, ou burocráticas que não cumprem o seu papel no controle das infecções.

"CCIH organizada de forma figurativa, apenas para cumprir as exigências da Vigilância Sanitária e do Ministério da saúde". E35, E15. 
“... existência de CCIH no papel, que não dá conta da gravidade e extensão do proble$m a^{\prime \prime}$. E11, E17.

"... não simplesmente montar comissões no papel para cumprir exigências da lei, mas efetivamente trabalhar, investigar e prevenir as infecções". E25.

Observamos uma clara percepção da profunda contradição existente nos serviços de saúde: "faz de conta" que se cumpre a legislação. Como se pode prevenir infecção, quando não se tem o mínimo indispensável que é um serviço estruturado que apoie, normatize, implemente e avalie as ações de prevenção e controle? Ressaltamos que as iniciativas positivas dependem do interesse, conhecimento e responsabilidade profissional.

As participantes deste estudo apontam que este problema é gerado pela inexistência de fiscalização, pelos órgãos competentes, no sentido de fazer cumprir a lei que determina a criação de comissões, em todos os hospitais, como explicitado:

"... falta de apoio do governo que cria leis, regulamentam mas não fiscalizam". E1.4.

"... que as leis fossem executadas e fiscalizadas". E12.

Outro desafio mencionado que se insere no arcabouço da estrutura organizacional faz parte do paradigma vigente nas políticas de saúde, que historicamente têm priorizado a saúde curativa em detrimento da preventiva.

“... descaso por parte dos governantes que não priorizam uma política de saúde e educação...". E34.

"As políticas de saúde privilegiam práticas de saúde curativa que são mais onerosas em detrimento de práticas preventivas". E19.

Para melhor compreensão dos desafios apontados pelas enfermeiras, retornaremos a algumas décadas quando as infecções hospitalares apareceram com maior intensida- de agravadas pelo crescimento do número de hospitais, na década de 70 , pela maior hospitalização, pelo uso de novas tecnologias diagnósticas e terapêuticas, em sua maioria invasivas, pela expansão da indústria farmacêutica e pela predominância das ações curativas.

Foi neste cenário sócio-político que se deu a repercussão das infecções hospitalares no Brasil, no final da década de 70 e início da década de 80 , desencadeadas por denúncias da população atendida nos hospitais públicos e privados, pela constante veiculação pela mídia que a questionava e incitava à reflexão e, principalmente, pela forma de gerir o credenciamento dos hospitais, determinado pela ausência de critérios e pelo repasse insuficiente de verbas pela Previdência Social.

Neste contexto, o Ministério da Saúde publicou a portaria 196 de 24 de junho de 1983 , o que representou a primeira medida governamental no sentido do controle das infecções hospitalares (2). Posteriormente esta portaria foi revogada e atualizada pela Portaria $n^{\circ}$ 930/92 (3), a qual em 1998 foi substituída pela portaria n. ${ }^{\circ}$ 2.616/98 (4).

A portaria, 196/83 representou um avanço, entretanto, apesar desta determinação regulatória, o Ministério da Saúde não disponibilizou os recursos necessários a sua efetivação e muito menos a sua fiscalização.

A implantação e funcionamento das $\mathrm{CCIH}$ ficaram a mercê do interesse institucional e, em muitos casos, ocorreram graças à iniciativa e empenho dos profissionais destas instituições.

Temos vivenciado uma evolução política com maior democratização do pais, entretanto, todo esse processo de mudança não tem sido suficiente para alterar as políticas de saúde a ponto de fazer diferença em programas específicos como o da prevenção e controle das infecções hospitalares e é, neste contexto de adversidade, que estes profissionais estão batalhando para controlar as infecções hospitalares cujas ações são basicamente preventivas. 


\section{Políticas Institucionais e Administrativas}

Além das políticas governamentais, os sujeitos deste estudo apontaram como desafios para o controle das infecções, as políticas existentes nas instituições de saúde e suas estruturas administrativas, destacando a falta de apoio da direção, baixa autonomia para as Comissões, política financeira da instituição, sucateamento das condições de trabalho, baixa remuneração, inadequação das estruturas físicas, pouca mão-de-obra qualificada para executar o serviço.

Na área hospitalar, utiliza-se muito a administração departamentalizada do tipo funcional, onde as atividades são agrupadas por especialistas e que, segundo Vecina Neto (15), favorece uma maior busca da eficácia organizacional. Entretanto, este modelo de departamentalização dificulta o reconhecimento dos objetivos da organização, não havendo transparência ao nível dos produtos (ações de saúde), não permitindo visualizar o cliente.

O reflexo desta política de administração hospitalar tem sido sentido pelas enfermeiras que trabalham no controle das infecções hospitalares.

“... condições socio-econômicas das empresa que prezam pela quantidade em detrimento da qualidade". E26.

"Administradores ... que resistem à implantação de medidas de controle por questões econômicas". E12.

"... administração que dificulta a implantação de normas e rotinas, processo burocrático para a aquisição de materiais essenciais de proteção coletiva e individual, materiais de limpeza e para desinfecção e esterilização". E25.

"... até sofrer com o desinteresse dos donos de hospitais que não se importa com a comissão, ... não se importa com os profissionais mal preparados que a empresa comporta". E03, E37.

"... enfermeira que acumula a função da CCIH e da supervisão de enfermagem e um médico fantasma que aparece de vez em quando no hospital". E37.
Estes relatos evidenciam os problemas decorrentes do sistema administrativo existente nos hospitais, no qual cada unidade departamentalizada funciona como uma atividade fim. Desta forma, importa que ela esteja funcionando mas não como está funcionando, se com qualidade e atingindo sua finalidade maior que é a qualidade no atendimento.

Outra questão elementar apontada pelos sujeitos foi a estrutura de planta física das instituições que não atendem as necessidades do controle de infecção.

"É evidente que a estrutura dos nossos hospitais deixa a desejar quanto a presença de lavatórios em pontos estratégicos". E06.

"Planta física inadequada, gerentes de saúde relutam em contratar profissionais da área de engenharia e arquitetura e assim, tem-se unidades bonitas, modernas, mas não funcionais, e aí começa as adaptações". E12.

Os recursos humanos disponíveis para as ações de controle foram, também, indicados como um desafio preocupante que, além de insuficientes, não são qualificados para essa tarefa. Questionou-se o papel formador das universidades, que não têm preparado os futuros profissionais para essa especialidade.

"As escolas como aparelho formador têm uma parcela grande de responsabilidade ... em contribuir para a formação de profissionais esclarecidos, orientados e comprometidos com a prevenção e controle da Infecção hospitalar". E09.

"... falta incentivos, cursos e orientações". E1.1.

“... se nas universidades a temática $\mathrm{CIH}$ fosse mais debatida, questionada, ensinada e aprendida, muitos problemas seriam resolvidos". E12.

A realidade do despreparo profissional em áreas específicas é evidente e reflete na qualidade das ações desenvolvidas. Conquanto seja este um problema óbvio, há que se des- 
tacar a constante evolução das práticas de saúde frente à emergência e ressurgência de novas doenças, novas tecnologias, novos paradigmas que exigem do profissional uma atualização contínua, através de leituras, participações em eventos, fóruns de discussão dentre outros.

As condições de trabalho de enfermeiros, determinadas pela política institucional e estrutura organizacional da saúde no país, nem sempre permitem ao profissional buscar essa atualização. Essas condições de trabalho foram citadas pelas participantes como desafios para o controle das infecções.

"Sucateamento das condições de trabalho e da prestação de serviços ao cliente". E26.

"Profissionais trabalham em condições inadequadas ...". E15.

"... excesso de trabalho do profissional, dupla ou tripla jornada de trabalho..." E15.

“.. má remuneração, desestímulo, falta de tempo para descanso e lazer, três empregos...". E26.

Observamos que as políticas institucionais não têm colaborado para a efetivação das ações de prevenção e controle, na medida em que não fornecem a infra-estrutura necessária para tal, não apoiam as ações de prevenção e controle determinadas pelas comissões e não oferecem condições adequadas à atualização profissional que se traduziriam em qualidade no atendimento.

\section{Relações de trabalho: interpessoais e intersetoriais}

As relações de trabalho tanto interpessoais quanto intersetorias também foram apontadas como desafios no controle das infecções hospitalares. O trabalho da CCIH é desenvolvido, na sua essência, junto aos diversos setores da instituição nas quais desenvolvese algum tipo de ação relacionada ao atendimento do cliente, alguns com maior e outros com menor possibilidade de ocorrer infecções hospitalares de acordo com o tipo e a invasividade dos procedimentos exigidos em cada unidade.

A estrutura administrativa departamentalizada favorece a tendência de gerenciar cada setor de forma igual, sem considerar sua especificidade, comparando-os entre si, gerando competitividade e relações conflituosas.

"Os profissionais que estão no controle, estão sempre interagindo com toda a equipe do ambiente hospitalar." E02, E26.

"... envolvimento efetivo de todas as áreas do hospital, cozinha, lavanderia, emergência, clínicas, limpeza, centro cirúrgico." E21, E22.

"... intercâmbio entre o serviço de controle de infecção hospitalar e demais setores afins, farmácia, laboratórios, setor de compras, controle de qualidade e outros." E02.

"... é necessário uma interação entre o setor administrativo e o operacional (SCIH)." E30.

"É preciso trabalhar a instituição como um organismo que necessita de conjunto para funcionar." E14.

Estes registros expõem as intrincadas relações profissionais, marcadas pelas relações de poder, interesses pessoais e domínio técnico que regem as forças de trabalho numa mesma unidade e entre elas. Estas forças de trabalho se interpõem a favor ou contra o controle das infecções, na medida em que compreendem e aceitam as ações de prevenção e controle implementadas pelo Serviço de Controle de Infecção Hospitalar (SCIH) como benéficas ou como instrumento controlador e de pressão sobre cada departamento.

\section{Normatização dos serviços}

Os registros das enfermeiras evidenciaram uma fragilidade dos serviços de controle que, em sua maioria, ressentem-se de normas e rotinas que deveriam reger as ações do serviço.

“...falta padronização de normas, rotinas, materiais a serem utilizados... " E02, E12. 
"... exige supervisão, planejamento e execução constante". E16.

"... disponha de rotinas e técnicas assépticas, condições adequadas de trabalho, recursos técnicos materiais e humanos para o desempenho de um trabalho satisfatório". E19.

"... é preciso trabalhar com normas, regimentos uniformes para todo o hospital". E14.

Parecem antagônicas essas colocações de enfermeiras que atuam no controle, uma vez que cabe ao serviço do qual elas fazem parte, quase sempre em tempo integral, propor, elaborar, implementar e supervisionar a aplicação de normas técnico-administrativas, visando à prevenção e ao tratamento das infecções hospitalares.

O que tem impedido a observação dos aspectos legais, apontados pelas enfermeiras como desafios? Dificuldades na elaboração de normas e rotinas que deverão ser observadas por outros setores e profissionais? Falta apoio administrativo para implantá-las e implementá-las? Resistência administrativa e profissional contra estas normas? Ou a própria dificuldade de normatizar serviços departamentalizados, onde cada um tem seu micropoder instalado?

Na verdade, evidencia-se uma não uniformidade de condutas na instituição, em relação ao controle de infecção hospitalar. Essa diversidade, além de expor falhas na estrutura administrativa das instituições, revela baixa qualidade nas ações por elas desenvolvidas.

\section{BATALHA BIOLÓGICA}

Aqueles que, apesar de todas as dificuldades, conseguem estruturar um serviço de controle de infecção hospitalar, esbarram em outros problemas, exigindo atenção especial como é o caso da evolução dos microrganismos que apresentam resistências cada vez mais importantes, determinadas pelo uso indiscriminado dos antimicrobianos, dentre outros.
"Na mesma proporção que avançamos nas medidas preventivas, os microrganismos adquirem resistência e matam indivíduos cada vez mais e com maior força". E02, E03.

“... já foram isoladas cepas resistentes à vancomicina. O que fazer? Parece estar fora de controle, ... é um problema em nível mundial". E10.

"Aumento do uso indiscriminado de antibióticos, microrganismos antibioticorresistentes". E05, E14, E15, E34.

Observamos duas questões relevantes: a primeira relaciona-se à rápida evolução dos microrganismos, mutação e resistência; a segunda diz respeito ao uso indiscriminado dos antimicrobianos.

Apesar da identificação destas duas facetas na batalha biológica, elas estão intimamente relacionadas e exigem uma análise conjunta. O surgimento dos antimicrobianos, nas décadas de 40 e 50, foi visto como um milagre capaz de controlar todas as doenças infecciosas que até então causavam mortes. Esta visão errônea ainda permanece e tem contribuído para o seu uso abusivo e muitas vezes incorreto.

A resistência dos microrganismos data do início da era antimicrobiana. Apesar dos genes que determinam a resistência a antimicrobianos existirem na natureza e precederem ao uso clínico destas drogas, esta resistência aumentou, consideravelmente, a partir do final da década de 60.

Algumas medidas precisam ser adotadas no sentido de minimizar o crescimento e essa capacidade de mutação dos microrganismos, dentre elas, a indicação consciente e fundamentada dos antibióticos, a vigilância e o isolamento de pacientes com cepas multirresistentes que têm demonstrado eficácia, sobretudo no controle dos Staphylococcus aureus resistentes à oxacilina.

Há que se destacar que as drogas antimicrobianas apresentam um grande recurso à terapêutica das infecções e sobretudo das hospitalares. Contudo, medidas de prevenção devem ser empreendidas no sen- 
tido de coibir as infecções, através de intervenções na cadeia de transmissão dos microrganismos e, principalmente, no emprego racional de antimicrobianos.

Embora pareçam medidas de fácil execução, apresentam grande resistência por parte dos profissionais, por considerarem que a comissão está interferindo na sua prática terapêutica.

\section{ENVOLVIMENTO PROFISSIONAL}

O controle das infecções hospitalares resulta de um esforço conjunto e da adoção de medidas sabidamente eficazes. Esse esforço conjunto depende da vontade de cada profissional envolvido nas ações de saúde, sejam elas preventivas ou curativas. A adoção das medidas de prevenção e controle estão relacionadas, fundamentalmente, ao conhecimento e às mudanças de comportamento dos profissionais, face à evolução da epidemiologia hospitalar e das constantes mudanças originadas por ela.

Os sujeitos deste estudo relataram fatos acerca do envolvimento profissional que tem dificultado as ações de controle, dentre eles a falta de conscientização do profissional acerca da importância das medidas de controle, a baixa adesão ás medidas de controle e pouco comprometimento com o serviço e paciente.

\section{Falta de conscientização profissional}

Em relação à falta de um maior envolvimento profissional o grande desafio sentido foi o da pouca conscientização profissional acerca das medidas de prevenção e controle como evidenciados nos relatos a seguir:

“... dificuldade em conscientizar os profissionais acerca do controle de infecção hospitalar". E05, E36, E38.

“... conscientização dos profissionais que lidam com o paciente de que é preciso atender as normas estabelecidas por essa comissão". E31.

“... não adianta treinamentos se a equipe não cooperar ... essa cooperação só é conseguida a partir do momento em que esses profissionais se consientizarem da sua importância". E14.

Evidencia-se uma certa ansiedade por parte dos que se dedicam ao controle das infecções, na medida em que não conseguem a observância da equipe às medidas de controle, estabelecidas pelas comissões.

Ações educativas no que se referem ao controle e prevenção de infecção hospitalar, segundo Camalionte (5), conduzem sempre à conscientização e feedback para a mudança de comportamento. Os profissionais em controle de infecção devem ser agentes de mudanças, sem medo de ousar no que refere-se à solução de problemas.

\section{Adesão às medidas de controle}

A adesão às medidas de controle está intimamente relacionada à resistência em mudar hábitos, conforme foi explicitado pelos sujeitos.

"É necessário ter profissionais que aceitem, respeitem e cumpram as normas estabelecidas para o controle". E22.

"... não adesão dos profissionais de saúde ao controle das infecções - lavagem das mãos, paramentação, áreas de isolamento ...". E15, E28.

"Complexidade de trabalhar com mudanças de pensamentos, técnicas e hábitos". E38.

"Profissionais resistem à mudança de hábitos, pois pensam que assim está funcionando". E34, E12.

"... muitas vezes demanda mudanças de atitudes, de comportamento, e nem sempre a direção e outros profissionais estão dispostos a mudar". E03.

A adesão a novas medidas é difícil de ser conseguida por profissionais de qualquer 
área do conhecimento por implicar mudança de hábito, que quase sempre é acompanhada de traumas e dificuldades inerentes à adaptação a situações novas.

Na área de saúde e, em especial, no controle das infecções hospitalares, significa mudanças de técnicas aprendidas e sedimentadas pela prática diária, incorporação de novos aparatos de proteção individual e coletiva, que inicialmente, exigem perseverança para a sua adaptação, pois até que passem a pertencer à rotina diária com naturalidade, parecem ser incômodos, restringem os movimentos, dificultam a percepção tátil, alteram a temperatura corporal, ou mesmo atrasam a execução do serviço pela simples alteração da rotina.

Observamos a citação freqüente da não adesão a medidas simples e de alta eficácia para o controle, como a lavagem das mãos. Esta medida de controle tem sido preconizada desde o final do século XIX $(10,13)$ e continua até hoje, sendo motivo de campanhas educativas para a sua adoção.

Está claro que embora importante, o conhecimento por si não garante a mudança de comportamento, esta depende da motivação que inclui, além do conhecimento, as habilidades, o nível de maturidade, atitudes e crenças. A credibilidade do agente de mudanças, no caso o educador, também influencia na mudança de atitude de quem a deve implementá-la (5).

\section{Comprometimento com o serviço e paciente}

Outro aspecto relevante apontado como desafios para o controle de infecção foi o comprometimento dos profissionais com o serviço e o paciente.

"Descaso dos profissionais de saúde". E09.

"... profissionais da área, pouco comprometidos com a saúde". E07, E34.

"Os profissionais de saúde ignoram ou até desconhecem o controle ou normas estabelecidas pela CCIH". E30. “...falta de compromisso por parte de determinados profissionais com o paciente e com o serviço ..." E03.

A sociedade capitalista, o mundo competitivo e os baixos salários tem levado as pessoas a exercerem suas atividades de forma mecânica, e a empreenderem jornadas duplas, e até triplas com uma carga horária excessiva . Estes fatores têm contribuído para o pouco envolvimento profissional, seja no que refere-se à atualização ou mesmo à observância de normas consideradas seguras para o controle de infecção.

O controle das infecções não se apresenta como um problema que deva ser resolvido apenas pelos profissionais das $\mathrm{CCIH}$ e $\mathrm{SCIH}$, mas por todos aqueles que dedicam-se a qualquer atividade na área de saúde. Comungamos com a compreensão de Teixeira \& Santos (14) quando consideram que o controle de infecção é uma responsabilidade moral e legal que torna a razão do trabalho verdadeira, a lei desnecessária e valoriza o profissional de saúde e a profissão.

\section{CAPACITAÇÃO PROFISSIONAL}

Um forte tom apareceu nos relatos sobre a educação profissional enquanto condição necessária à atuação em nível do controle de infecção hospitalar. Formas de capacitação profissional foram apontadas como a educação continuada, o treinamento de recursos humanos e a atualização profissional.

\section{Educação continuada}

A educação continuada compreende o treinamento contínuo em serviço, visando a capacitação e a qualificação dos recursos humanos, tanto do ponto de vista técnico, quanto do relacionamento humano, para a execução de suas atividades laborais, que segundo Khoury \& Elias (7) direta ou indiretamente deve refletir os objetivos finais da instituição. 
De acordo com estes autores os programas de treinamento, orientação e acompanhamento visam corrigir desvios, ou sanar deficiências de desempenho. Entretanto, chamam a atenção para os esperados processos de mudança que só se efetivarão na medida em que os envolvidos participarem na análise e decisão sobre as mudanças.

"Manter a educação continuada efetiva e atualizada, promovendo cursos e treinamentos em serviço". E02.

"... treinamento e capacitação técnica de profissionais de enfermagem que às vezes se limita a eles... a educação continuada deve trabalhar com toda a equipe multiprofissional". E30.

"Educação continuada para atualização e capacitação dos profissionais de saúde, pois a educação é comprovadamente o melhor caminho para alcançar as transformações". E21, E27, E33.

Estes profissionais trabalham no dia-a-dia, presenciando a dificuldade de operacionalização das ações em saúde de forma contundente e segura para ele, profissional e para o paciente.

Reconhecem a efetividade da capacitação profissional, têm dificuldades em colocá-la em prática, por falta de infra-estrutura, de apoio administrativo e, até mesmo, falta de interesse dos profissionais em participar.

Merece destaque, um fato abordado pelos sujeitos acerca da capacitação profissional, de que ela deve ser dirigida a toda a equipe multiprofissional e não apenas a equipe de enfermagem como tem acontecido.

\section{EPIDEMIOLOGIA DAS INFECÇÕES}

As ações de controle de infecção devem ser baseadas na epidemiologia das infecções do hospital. Desta forma, torna-se obrigatória a sua caracterização, visando à objetividade do controle. Pelos relatos dos sujeitos, detectamos que esta etapa do processo de controle, ainda representa um desafio como evidenciado a seguir:
“... levantamentos epidemiológicos como forma de investigar e identificar as causas da infecção...". E33.

"... conhecimento da epidemiologia hospitalar, ... é impossível controlar aquilo que não se sabecomo, quando e quanto ocorreu ou está ocorrendo". E36.

"Vigilância epidemiológica sistemática pelo SCIH é necessária para o diagnóstico da situação da instituição para a atuação da comissão ou do serviço de controle". E12.

As enfermeiras do estudo demonstram a compreensão da importância da vigilância epidemiológica para o planejamento das ações de controle. Porém, evidenciam que esta atividade não tem sido realizada de forma sistematizada.

Os dados compilados pela vigilância epidemiológica geram relatórios que, ao serem interpretados, fornecem subsídios aos controladores de infecção, que norteiam as medidas de controle (6).

Como esta etapa do controle é importante muitos a empreenderam com muito critério, conhecendo suas taxas de infecção, estratificadas por topografias, clínicas e equipes com a confecção de gráficos e emissão de relatórios. Contudo, as ações resumiam-se na vigilância epidemiológica sem que esta desencadeasse ações de controle.

Lacerda \& Egry (9) chamam a atenção para a supervalorização dada à coleta de dados e ao estabelecimento de indicadores epidemiológicos, que ocupam quase todo o tempo da enfermeira da $\mathrm{CCIH}$, transformando, muitas vezes, seus resultados mais como um fim em si mesmo do que como meio para subsidiar as ações de controle.

\section{MEDIDAS DE PREVENÇÃO E CONTROLE}

Uma preocupação freqüente para os que controlam infecção hospitalar é a implementação de medidas de prevenção e controle, objetivo maior desses programas. As enfermeiras também apontaram essas medidas 
como desafios para o controle de infecção como exposto a seguir:

“... infinidade de questões relacionadas com o controle que devem ser levadas em conta limpeza, desinfecção de áreas e artigos, esterilização... “. E08, E38.

“... questões associadas a procedimentos invasivos, diagnósticos e terapêuticos, a técnicas adequadas de limpeza, desinfecção, esterilização, assepsia e anti-sepsia". E03, E08.

"... atender as normas estabelecidas como lavagem correta das mãos, o desenvolvimento de técnicas assépticas, a esterilização dos materiais...". E31.

"... é necessário a validação da esterilização, produtos eficazes, testes microbiológicos e outros". E17.

Estes relatos exibem várias facetas do programa de controle de infecção e a interrelação das medidas de prevenção e controle. Embora pareça simples a implementação dessas medidas, depende das políticas institucionais e administrativas, da normatização do serviço, das relações interpessoais e intersetoriais, do envolvimento e da capacitação profissional.

Na verdade, dada a pluralidade das ações a serem desenvolvidas e a estrutura inadequada para o funcionamento da $\mathrm{CCIH}$, os enfermeiros que se propõem a controlar infecção hospitalar vêem-se em constante conflito e terminam por intervir em situações emergenciais, sem dar conta da execução de um programa maior que contemple todas as vertentes do controle de infecção.

De acordo com Lacerda \& Egry (9) tudo isso leva a crer que a mera existência de $\mathrm{CCIH}$, nessa forma de processo de trabalho, não se constitui em condição suficiente, senão desnecessária, para solucionar o problema das infecções hospitalares.

Ademais, frente a tantos desafios, vale a pena ressaltar que persistência, consciência crítica e vontade constantes são elementos essenciais para o profissional que se propõe a atuar na área de prevenção e controle de infecção.

\section{CONSIDERAÇÕES FINAIS}

As enfermeiras, sujeitos deste estudo, apontaram vários desafios para o controle de infecção nas instituições de saúde, refletindo a experiência de cada um em relação às dificuldades vivenciadas no enfrentamento deste problema.

Dos relatos, extraímos seis pontos considerados pelas enfermeiras como desafios para o controle de infecção com seus respectivos desdobramentos:

-Estrutura organizacional (políticas governamentais; políticas institucionais e administrativas; relações de trabalho interpessoais e intersetoriais, e normatização dos serviços).

-Batalha biológica.

-Envolvimento profissional (falta de consciência; adesão às medidas de controle e; comprometimento com o serviço e paciente).

-Capacitação profissional (educação continuada e; atualização profissional).

-Epidemiologia das infecções.

-Medidas de prevenção e controle.

Os desafios encontrados vão desde a adoção de medidas simples de controle até a complexa estrutura organizacional das instituições normatizadoras, provedoras e executoras. Entretanto, os maiores desafios explicitados foram as políticas instituídas, as relações de trabalho e o pouco envolvimento profissional.

Os dados evidenciam que as enfermeiras participantes deste estudo não só conhecem os desafios para o controle de infecção mas, também, sofrem o impacto decorrente das dificuldades encontradas para a sua execução.

\section{REFERÊNCIAS BIBLIOGRAFICAS}

1. BARDIN, Laurence. Análise de Conteúdo. Lisboa, Edições 70 Ltda., 1997, 226 pp.

2. BRASIL. Leis, decretos, etc. Portaria $N^{\circ} 196$ de 24 de junho de 1983. In: BRASIL. Ministério da Saúde. Manual de controle de $\underline{\text { de }}$ infecçãa $\underline{\text { ho }}$ hospitalar. 
Brasília, Centro de Documentação Científica do Ministério da Saúde, 1985. pp.101-105.

$3 . \quad$ Leis, Decretos, etc. Portaria No 930 de 27 de agosto de 1992. Dispõe sobre novas normas gerais para o controle de infecções hospitalares e revoga a Portaria No 196/83. D.O.U., Brasília, 4 de setembro de 1992. Seção I, pp.1279-1282.

$4 . \quad$ Portaria $\mathrm{N}^{\mathrm{o}} 2.616$ de 12 de maio de 1998. D.O.U Dispõe a respeito do controle da infecção hospitalar. Brasília, 13 de maio, 1998.

5. CAMALIONTE, Mariza Landolpho Vicca. Aprimoramento de recursos humanos para o controle de infecção. In: FERNANDES, Antônio Tadeu.; et al. Infecções Hospitalares e suas interfaces na área de saúde. São Paulo. Atheneu, 2000. pp.1679-1685.

6. FERNANDES, Antônio Tadeu; FERNANDES, Maria Olívia Vieira. Vigilância epidemiológica das infecções hospitalares. In: FERNANDES, Antônio Tadeu; et al. Infecções hospitalares e suas interfaces

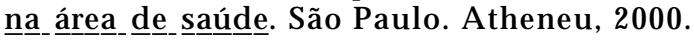
pp.1402-1418.

7. KHOURY, Hala Jamil; ELIAS, Margareth A. Barbosa. Recursos humanos e o controle de infecção. In: FERNANDES, Antônio Tadeu; et al. Infecções Hospitalares e suas interfaces na área de saúde. São Paulo. Atheneu, 2000. pp.1671-1678.

8. LACERDA, Rúbia Aparecida; et al. Infecções hospitalares no Brasil. Ações governamentais para o seu controle enquanto expressão de políticas sociais na área de saúde. Revista da Escola de Enfermagem da USP, São Paulo: 30(1): 93-115. 1996.
9. LACERDA, Rúbia Aparecida.; EGRY, Emiko Yoshikawa. As infecções hospitalares e sua relação com o desenvolvimento da assistência hospitalar : reflexões para a análise de suas práticas atuais de controle. Revista Latino-americana de enfermagem Ribeirão Preto, São Paulo: 5(4):13-23. 1997.

10. NIGHTINGALE, Florence. Notas sobre enfermagem: o que é e o que não é. São paulo, Cortez, ABEn/CEPEn, 1989. 174 pp. Tradução de : Notes on nursing. What it is, and what it is not.

11. PEREIRA, Milca Severino. Infecção hospitalar no Brasil: um enfoque para o seu controle. Ribeirão Preto, São Paulo, 1987. Dissertação (Mestrado) - Escola de Enfermagem de Ribeirão Preto da USP.

12. PEREIRA, Milca Severino; et al. Infecções hospitalares e seu controle: problemática e o papel do enfermeiro. Revista da Escola USP., São Paulo: 27(3):355-361. 1993.

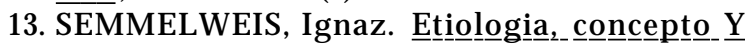
profilaxis de la fiebre puerperal. Extracto de Ignaz Semmelweis, The etiology, concept, and prophylaxis of childbed fever. Traducido por K. Codell Carter. Madison. The University of Wisconsin Press. 1983. pp. 47-62.

14. TEIXEIRA, Mauro; SANTOS, Márcio Vieira. Responsabilidade no controle de infecção. Revista da Associação Paulista de Cirurgiõos Dentistas, São Paulo: 53(3):177-189, 1999.

15. VECINA NETO, Gonzalo. Noções de administração hospitalar. In: FERNANDES, Antônio Tadeu; et al. Infecções Hospitalares e suas interfaces na área de saúde. São Paulo. Atheneu, 2000. pp. 1691-1699. 